\title{
NARRATIVA Y GÉNERO: SOBRE DESIGUALDAD Y JUSTICIA SOCIAL EN VILLETTE DE C. BRONTË E INSOLACIÓN DE E. PARDO BAZÁN
}

\author{
Cristina Monereo Atienza ${ }^{1}$
}

\begin{abstract}
RESUMEN: En este trabajo se analizan dos obras literarias que retornan a los orígenes del movimiento feminista y plantean una crítica a la sociedad patriarcal, la división de roles y la concepción marginada de la mujer en ese momento. Son ambos textos críticos que representan a un individuo aislado e indefenso en una sociedad dominada por el pensamiento y la beneficencia de la Iglesia; reflejan una sociedad naturalmente organizada en la que se ocultas o invisibilizan las desigualdades de género, disfrazadas como pura y simple cuestión de diferencia de/entre sexos; una sociedad donde se idealizan unas supuestas características femeninas (la belleza, la delicadeza, la sensibilidad) bajo las que esconde la auténtica dominación del sexo masculino; incluso, en las que domina el mito de la incomprensibilidad y el misterio que despiertan las mujeres como una forma de sumisión a la racionalidad masculina. Ante tal situación, se provoca a la mujer para levantar su voz diferenciada, plantando la semilla para crear un nuevo sujeto con libertad para generar proyectos de vida digna independientemente del sexo. A nivel público se establecen las bases para la reconstrucción de una sociedad que no separe artificialmente entre la esfera pública y privada, y en la que predomine una nueva teoría de la justicia basada más en la pluralidad y diferencia de expectativas, necesidades y bienes.
\end{abstract}

Palavras Clave: Brontë; Villette; Pardo Bazán; Insolación; feminismo; identidad femenina.

1 Doctora en Derecho (cum laude) por la Universidad Carlos III de Madrid. Profesora titular de Filosofía del Derecho en la Universidad de Málaga (UMA). Málaga, España. ORCID: https://orcid.org/o0oo-0002-9947-0111. E-mail: cmonereo@uma.es 
La justicia humana se me presentó bajo un nuevo aspecto: una loca aventurera ataviada de rojo, con los brazos en jarras.

La vi en su casa, antro de confusión;

los criados acudían a pedirle órdenes y ayuda que no daba; los pobres permanecían en su puerta, moribundos y descuidados; un enjambre de niños enfermos y turbulentos se arrastraban a sus pies y le lanzaban llamadas pidiendo simpatía, cuidados, educación.

La honrada mujer no se ocupaba de nada.

Tenía un cómodo asiento propio cerca de la lumbre, una pipa para solazarse y una botella de jarabe calmante. Fumaba, bebía y disfrutaba de su paraíso, y cuando algún lamento de los desgraciados herían demasiado vivamente sus tímpanos, mi hermosa dama cogía el atizador y, si el ofensor era débil, enfermo y agraviado, daba buena cuenta de él; si era fuerte y violento, sólo le amenazaba, hundía luego la mano en la profundo bolsa y le arrojaba una generosa lluvia de terrones de azúcar

(Brontë, 1996, p. 381-382)

Habla por su boca la justicia (Pardo Bazán, 2001, p. 208).

\section{INTRODUCCIÓN: LA MIRADA FEMENINA A TRAVÉS DE LA NOVELA DEL SIGLO XIX}

El propósito de estas páginas es realizar un breve análisis jurídicofilosófico y social de dos obras narrativas: Villette de Charlotte Brontë, e Insolación de Emilia Pardo Bazán. Con ello me propongo estudiar la cuestión social femenina planteada en la ficción realista del siglo XIX. El examen de una novela nunca es fácil ya que se trata de una expresión artística de la vida desde el conflicto, la contradicción y la duda; esto es, una fuente rebosante de preguntas cruciales que no responde a ninguna cuestión en particular. Por esta razón, me limito a descubrir la mirada femenina en la sociedad decimonónica al ser ésta de gran ayuda para comprender el pensamiento actual en materia de género.

Villete es uno de los escritos más singulares de Charlotte Brontë, a través del que es posible el retorno a los orígenes del movimiento feminista. Brontë fue una novelista inglesa nacida en 1816, cuyas obras transcendieron la época victoriana para convertirse en clásicas. Sus creaciones son atrevidas. En ellas domina la tensión entre lo romántico y lo anti- 
romántico, así como la fuerza crítica de un mundo dominado por hombres y, concretamente, del lugar que los hombres han reservado a las mujeres en ese mismo mundo. La obra literaria de Brontë está plagada de pensamientos, guiños y afirmaciones que hacen entrever una visión y una idea global de mundo distinta al sistema patriarcal, todavía hoy, impuesto. Lleva a cabo una crítica mordaz a la capacidad de juicio espontánea que permite a una clase dominante determinar qué sistema político y social es merecedor de apoyo. Se percibe una lucha contra el argumento político esteticista utilizado para mostrar una sociedad orgánica y bella que se erige, sin embargo, desde una retórica bajo la que oculta un sistema de poder basado en la propiedad heredada y la condición social. La idea de las mujeres bellas (delicadas, agradables, suaves) sirve para negarles el ejercicio de la razón y, también, de la moralidad y el sublime heroísmo (Shiner 2004, p. 231). En una de las obras maestras de Brontë, Jane Eyre, la protagonista afirma que:

Se supone que las mujeres deben ser generalmente muy tranquilas, pero las mujeres sienten igual que los hombres (Brontë, 1998, p. 140-141).

El libro ahora analizado es la obra más madura de Charlotte, cuyo estilo y trasfondo se ha visto gradual y dolorosamente emancipado de las falsificaciones y los mitos del melodrama y la novela rosa. En él, con un tono clave de crítica feminista, se representa a un individuo aislado e indefenso (una anti-heroína, más que heroína) que responde a la experiencia de la vida con un máximo de intensidad. Lucy Snowe subraya de manera inteligente y sutil que las mujeres se consideran inferiores a los hombres y que, por tanto, tienen que actuar en consonancia con lo que se espera de ellas. Lucy es pobre, no tiene familia ni atractivo o encanto personal y se ve obligada a sobrellevar sola esa situación cuanto mejor puede, consciente de que no va a recibir ninguna ayuda de instituciones sociales. Rompe, así, el lazo con su amargo pasado en Inglaterra y marcha al continente en busca de un mejor futuro. Es empleada como profesora en una escuela convertida en un pequeño universo ajeno al mundo. No obstante, la protagonista va ampliando ese mundo y buscando, no sin dificultades, su propio camino. En esta novela los problemas de la pobreza y la sumisión de la mujer aparecen íntimamente unidos y forma mucho más incisiva que en otros textos anteriores de la escritora, especialmente porque 
se sitúa en Francia, un país católico dominado por el pensamiento y la beneficencia de la Iglesia, y, además, centro de las revoluciones burguesas defensoras de la libertad y la igualdad.

Por su parte, Insolación presenta de manera muy crítica y audaz la situación de la mujer en la España decimonónica. Encuadrada dentro de la corriente del naturalismo español, esta novela describe una sociedad de entes individuales y heterogéneos que cumplen roles específicos preservados por una serie de normas fruto de un pacto social, entre ellas formales establecidas por la autoridad civil y, también, informales nacidas de la propia sociedad civil y la Iglesia (Rivero Moreno, 2004). Se analiza, pues, la influencia que el medio tiene sobre el individuo y las consecuencias que se pueden derivar de la trasgresión de las normas impuestas. Cuando aparece Insolación, el feminismo había dado ya sus primeros pasos fundamentales en España. Sin embargo - desde Benito Feijoo con su Defensa de la mujer (1726) hasta Concepción Arenal, con La mujer del porvenir (1869) - todos los esfuerzos protofeministas se habían limitado a la labor de rescatar a la mujer de su inferioridad intelectual y moral. Sin embargo, Pardo Bazán realiza una fuerte crítica de la división de roles sociales poniendo las técnicas de narración naturalista al servicio del objetivo emancipador de la mujer.

$\mathrm{Su}$ narrativa permite una lectura apasionada gracias a su visión abierta y rompedora. Como nunca antes se había atrevido nadie, la autora construye un cuadro de la Galicia de hace un siglo, ancestral, bárbara y violenta, en Los pazos de Ulloa y en Cuentos de la tierra. Además, en La Tribuna describe las fábricas del capitalismo decimonónico, después de haberse internado a observar en acción la vida de las obreras del tabaco y sus lamentables condiciones laborales. Y con esta novela también habló en plena época victoriana de la sexualidad de las mujeres y de su derecho al deseo.

Insolación es la historia de una aristocrática viuda de treinta y pocos años que, durante la romería de San Isidro, acepta la compañía de un joven andaluz con reputación de mujeriego, sin conocer de él apenas mucho más. Las descripciones de la marea popular, la muchedumbre goyesca, la música y el baile, los gitanos, las orillas del río Manzanares, el vino, las comidas humeantes, el terrible calor y el sol de Castilla, identifican la atracción por 
ese hombre como algo abrasador e incontrolable, como una insolación. El erotismo acaba en un encuentro sexual deseado por la protagonista y el relato se cierra con la decisión de ambos personajes de unirse en matrimonio.

Se trata, pues, de una novela con final feliz, muy diferente a otras muchas de su misma época, como La Regenta (1885) de Clarín o Tristana (1892) de Benito Pérez Galdós, donde la mujer aparece siempre como un ser misterioso e incomprendido, necesitado de protección y educación, y que en caso de infringir las normas sociales es sujeto de las consecuencias más terribles, como el ostracismo social, la desacreditación personal o, incluso, la muerte. Frente a las dos moralidades sociales diferenciadas, la del hombre y la de la mujer, Pardo Bazán opta por la igualdad de género. En el libro se contienen fragmentos tan significativos como éstos:

Señor, ¿̇por qué no han de tener las mujeres derecho para encontrar guapos a los hombres que lo sean, y por qué ha de mirarse mal que lo manifiesten (aunque para manifestarlo dijesen tantas majaderías como los chulos del café Suizo)? Si no lo decimos lo pensamos, y no hay nada más peligroso que lo reprimido y oculto, lo que queda dentro (Pardo Bazán, 2001, p. 94).

O también este otro:

¿Qué tiene de particular que salga V. a tomar el fresco en compañía de un amigo formal? Cuidado que son majaderas las fórmulas sociales. Yo puedo ir a su casa de V. y estarme allí las horas muertas, sin que nadie se entere ni se ocupe, y luego, si salimos reunidos a la calle media hora... cataplum (Pardo Bazán, 2001, p. 194).

Algunos discuten sobre la convencionalidad del final en matrimonio considerándolo un modo de confirmar una norma social. No obstante, otra interpretación podría también ser que la introducción de un final feliz en la historia de una mujer trasgresora social es una manera aún más provocadora de plantear la cuestión. La mujer que se revela no tiene porqué ser juzgada o castigada de ninguna manera. Muy al contrario, puede ser feliz, incluso del modo social más convencional. En definitiva, esta obra, cuando por entonces el género novelístico tenía una recepción lectora principalmente femenina y cumplía una función didáctica respecto de los roles de la mujer, alentaba hacia un cambio en la representación de lo femenino muy distinto del establecido para la mujer desde el dominio hegemónico masculino, y ciertamente podía así generar consecuencias 
importantes y perturbadoras, por lo que no es de extrañar que suscitara la airada reacción de muchos escritores, como José María Pereda e, incluso, el mismo Leopoldo Alas "Clarín" (Mayoral, 1995, p. 14). En Insolación se defendía y proclamaba la libertad de elección de la mujer y la injusticia del pacto social vigente.

\section{LOS ORÍGENES Y EL DESARROLLO DE LA VISIÓN FEMINISTA DE LA IGUALDAD. EN CONTRA DE LAS DIFERENCIAS NATURALES ENTRE MUJERES Y HOMBRES}

Como se ha visto, ambas novelas reflejan una sociedad naturalmente organizada en la que se ocultas o invisibilizan las desigualdades de género, disfrazadas como pura y simple cuestión de diferencia de/entre sexos (Mackinnon, 1995, p. 428). Hombres y mujeres aparecen diferenciados. Está, por un lado, el hombre caballeroso, fuerte y protector, culto y, sobre todo, racional y libre para hacer y decidir su propia vida. Por otro, se encuentra la mujer delicada, débil, sensible a las palabras, a la música, buena ama de casa, pero dominada por los sentimientos y, por ello, incapacitada para controlar su propia vida, resultando así para su protección inevitablemente recluida en el habitáculo establecido por los hombres y la sociedad que le rodean. La protagonista de Villette, Lucy Snowe apunta que:

\footnotetext{
Una mujer inteligente, al parecer, era algo así como un lupus naturae, un accidente desgraciado, una cosa para la cual no existían ni lugar ni empleo en la creación; no deseada ni como esposa ni como trabajadora [...] Y en cuanto a trabajar, solamente la mente viril podía hacerlo con algún resultado práctico beneficioso (Brontë, 1996, p. 338).
}

Es decir, hombre y mujer eran distintos y complementarios. Y parecía que no podía ser de otra manera.

En este contexto socio-cultural se idealizan unas supuestas características femeninas (la belleza, la delicadeza, la sensibilidad) bajo las que esconde la auténtica dominación del sexo masculino. Incluso, se expande el mito de la incomprensibilidad y el misterio que despiertan las mujeres como una forma de sumisión a la racionalidad masculina. 
En Villette la autora refleja con inteligencia cómo las mujeres han de formarse a fin de adaptarse mejor a ese patrón de belleza y sensibilidad socialmente establecido. Por ejemplo, se explica que:

Los extranjeros suelen decir que sólo a las muchachas inglesas se les permite viajar solas, y se asombran e incluso se escandalizan ante la temeraria confianza de los padres y tutores ingleses. En cuanto a las jóvenes misses -cuya intrepidez suele ser calificada de masculina e inconveniente por algunos-, son consideradas, en general, como víctimas pasivas de un sistema educativo que las dispensa de toda vigilância (Brontë, 1996, p. 55).

En Insolación se afirma:

Sucede que se nos imponen [las reglas], y que por obedecerlas, una mujer de instintos nobles se juzga manchada, vilipendiada, infamada por toda su vida a consecuencia de un minuto de extravío y, de no poder casarse con aquel a quien se cree ligada para siempre jamás, se anula, se entierra, se despide de la felicidad por los siglos de los siglos amén... Es monja sin vocación, o es esposa sin cariño... Ahí tiene V. donde paran ciertas cosas (Pardo Bazán, 2001, p. 202).

Por tanto, el carácter de la mujer era domesticado, controlado, apaciguado para poder adaptarse al patrón masculino establecido.

Ante tal situación de subordinación encubierta, la mujer comienza por expresar su rabia ante el rechazo y la marginación, es decir, por levantar su voz diferenciada para hacerse oír y denunciar sus circunstancias. Se despliega, entonces, la "conciencia diferencial" de las mujeres que ataca de base la supuesta igualdad formal entre los sexos implantada en la legislación liberal. La Declaración francesa de los Derechos del Hombre y del Ciudadano de 1789 establecía que todos eran iguales ante la ley. Frente a esta afirmación, la también escritora Mary Wollstonecraft desmantela la supuesta neutralidad del régimen liberal igualitario en el ejemplar libro Una reivindicación de los derechos humanos ${ }^{2}$. No puede existir igualdad en una concepción del mundo que ignore jurídicamente las diferencias circunstanciales de los individuos en la sociedad establecida. La igualdad formalmente reconocida no es acorde con las diferencias reales entre los sexos. A la mujer le es asignado un rol que la encasilla dentro de un mundo y la imposibilita para ejercitar realmente su libertad. En la sociedad liberal

2 La obra, cuyo título original en inglés es $A$ Vindication of the Rights of Woman, fue publicada por primera vez en 1792, en el Reino Unido. 
no existe para la mujer la igualdad ni la capacidad real para ejercitar la libertad (Sen, 2000). Lo que se ignora en este sistema es la manera en que las propias condiciones sociales también llegan a producir limitaciones en las elecciones de ciertas mujeres, cuyo estilo de vida se ve relegado por tradición al ámbito familiar³.

Las conexiones entre igualdad y libertad muestran que no es suficiente con plasmar en textos jurídicos la dimensión formal de estos valores y que, por el contrario, es necesario ponerlos en práctica y adaptarlos al contexto concreto de los individuos. La lucha por conseguir este objetivo se encauzó históricamente para admitir a un grupo socialmente excluido del poder político y social, el proletariado. En esa lucha histórica la marginación de género no se tuvo en cuenta como factor de desigualdad, a pesar de que era asimismo un problema que incidía transversalmente en todos los ámbitos de la vida y que afectaba por igual a todas las capas sociales.

Se reprocha ahora lo que Ibsen llama la "tragedia actual", esto es, que la mujer sea juzgada según la ley del hombre, como si no fuera una mujer sino un varón (Ibsen, 2005, p. 11). La mujer no es ella misma en la sociedad machista porque tiene que actuar conforme al rol asignado por el hombre. Se trata de una sociedad dominada por una única racionalidad. Así pues, las diferencias clásicas entre mujeres y hombres son artificiales. La mujer vista como ser débil, sensible, necesitado de protección es parte de esa diferencia instaurada desde la perspectiva masculina que tiene consecuencias a nivel político-jurídico y económico-social.

La teoría de los dos sexos inconmensurables es, por tanto, una teoría moderna que se desarrolla a lo largo de los siglos XVIII y XIX hasta hoy. El sexo tal y como se conoce es un "invento de la modernidad" (Laqueur, 1994, p. 335 et seq.). La mujer no es inferior, ni más débil, ni necesitada, y tampoco complemento de nadie. Esto no es más que un rol "naturalizado" (Osborne, 1993, passim) que llega a un "esencialismo de la diferencia”, poco favorecedor a la lucha feminista por la autonomía. Esta idea queda muy bien reflejada en uno de los personajes de Insolación, Gabriel Pardo, amigo

3 Todavía hoy se utiliza el argumento de que son las mismas mujeres las que rechazan, por ejemplo, trabajos de alta responsabilidad y salario (Nagel, 1989; Sher, 1975). 
de la protagonista y voz de la propia autora. Afirma que puede decir de corrido los diez mandamientos y que

\begin{abstract}
se me figura que rezan igual con Vds. que con nosotros...ningún confesor le dirá a V. que hay un pecado más para las hembras. Es decir que la cosa queda reducida a las consecuencias positivas exteriores... al criterio social (Pardo Bazán, 2001, p. 205-206).
\end{abstract}

Una biología de la inconmensurabilidad sexual ofreció una explicación al hecho de que las mujeres estaban ya subordinadas al hombre en el estado de naturaleza. El sujeto racional sin género engendra de esta forma sexos realmente opuestos y condicionados por la desigualdad. La diferencia en el género se presenta como una diferencia en el sexo biológico en términos científicos, cuando en realidad no es más que un producto cultural (Fernández-Llébrez, 2004, p. 95) ${ }^{4}$. La teoría feminista ha actuado a través de su conciencia diferencial en cierto modo como motor de deconstrucción de la sociedad patriarcal, pero siempre con la intención de pasar luego a su reconstrucción a efectos de emancipación de los grupos marginados.

3 LA CRÍTICA DE LA IGUALDAD FORMAL Y LA BÚSQUEDA DE LA SUSTANCIAL. HACÍA UN ESPACIO SOCIAL AMPLIADO Y UNA NUEVA CONCEPCIÓN DEL CONTRATO Y LA JUSTICIA SOCIAL

Resulta difícil hablar de la lucha feminista desde el punto de vista jurídico. Como ocurrió con el primer socialismo, el feminismo se ha mostrado muy crítico con los instrumentos del Estado y el Derecho por considerarlos formas que incorporan una determinada racionalidad y que, debido a ello, pueden utilizarse como mecanismos de mantenimiento del status quo (Atienza, 2007, p. 253 et seq.). Al igual que el socialismo atacaba al Estado y el Derecho burgueses, el feminismo también desconfió del sistema estatal y jurídico de raíz patriarcal. No obstante, tal desconfianza se refiere exclusivamente a un determinado modo de ver y pensar el sistema jurídico. Desde otro punto de vista, el Estado y el Derecho suponen métodos muy eficaces de transformación y progreso social, capaces de incorporar las propuestas feministas.

4 Una defensa de las diferencias de género partiendo de las diferencias biológicas del sexo está en Steven Goldberg (1976, p. 23-28). 
Así pues, la lucha debe ser contra el sistema de racionalización jurídica patriarcal y no contra los instrumentos a través de los cuales se desenvuelve éste. Es cierto que, como también le ocurrió a las reivindicaciones socialistas, las propuestas feministas han tenido que minimizarse para adecuarse al funcionamiento del sistema establecido. Esta es la razón de que las leyes siguen hablando en términos de diferencias de sexos, pero siempre como medio para la eliminación de la desigualdad de género (Atienza, 2007, passim).

El objetivo sería eliminar el sexo del debate jurídico, político y económico (Herrera Flores, 2005, p. 66) a partir de un cambio sociocultural y, también, de una transformación institucional resultado de un nuevo contrato social que incluya a ambos sexos en las decisiones públicas y privadas. No se puede llevar a cabo ese cambio únicamente a partir de reformas normativas. Éstas deben ir acompañadas también de innovaciones estructurales e institucionales. Se requiere un esfuerzo constructivo, y mejor de reconstrucción, de esa realidad social a partir de un nuevo sujeto político democrático (Young, 1990, passim) capaz de eliminar la separación artificial entre la esfera pública y privada. La búsqueda debe dirigirse a crear de forma libre proyectos de vida digna, independientemente del sexo. La diferencia ahora aparece como recurso público a garantizar y lo hace para erradicar la perspectiva del género en el discurso político-jurídico.

Ha de hacerse hincapié en que las mujeres se han visto recluidas al ámbito privado y, así, silenciadas en el discurso público que partía de una concepción naturalista de la sociedad de corte patriarcal. En las sociedades liberales igual que se podían imponer normas del "buen gusto", también existía un discurso estético para justificar el sistema político-jurídico y social (Shiner, 2004, p. 229 et seq.). La sociedad bella y justa era la concebida por el hombre blanco, burgués, cuya visión diferenciaba roles de género para relegarlos a diferentes parcelas de la vida. La mujer se veía imposibilitada de salir de su habitáculo privado. Esta situación es denunciada en las novelas de Brontë y de Pardo Bazán quienes, además, plantean una alternativa a ese punto de vista. Ello permite idear hoy otra posibilidad: la construcción de un espacio social ampliado que involucre el ámbito público y el privado, y que contribuya a un tipo de acción político- 
social interactiva y relacional, que presente conjunta y dialécticamente los dualismos de esencia ontológica de género (Herrera Flores, 2005, p. 95 et seq.; Biase, 1998). La manera de construir este espacio no puede basarse en identidades esencialistas y en "discursos racionales a priori" ${ }^{5}$, reductores de la complejidad social. No debe buscarse un espacio social homogéneo en el que al final del proceso político-jurídico se llegue a unas mismas conclusiones, a la manera del patriotismo habermasiano. La lucha pretende conformar un contexto complejo de diferencias reconocidas y de mínimos universales contrapuestos.

Estaríamos ante un intento diferente de recuperar la exigencia de universalidad, como imprescindible desde el punto de vista ético y jurídico, es decir, ante una comprensión de la diferencia que, en lugar de subrayar la posibilidad de consenso pese a la diversidad, ponga el énfasis en que no hay consenso sino desde la diversidad. Desde el punto de vista del pluralismo cultural, esto comportaría el reconocimiento del carácter valioso de todo punto de vista (si bien siempre susceptible de discusión), de forma que el diálogo parte de esa premisa, sin que ello impida avance, antes bien lo favorezca, hacia la "interpelación mutua de unas tradiciones por otras, donde no se escamoteen ni los presupuestos antropológicos, ni tampoco los méritos y/o responsabilidades históricas en ese campo; donde se haga posible, en fin, la autocrítica sincera de cada tradición en cuanto a su contribución al respeto y promoción de los derechos humanos" (Lucas, 1994, p. 259) ${ }^{6}$.

Las identidades no son, por tanto, un conjunto de atributos fijos. Constituyen, por el contrario, un proceso político complejo de interacciones que precisa ser reconocido y representado en unas instituciones renovadas7. La meta de las teorías feministas debería ser superar las políticas de discriminación positiva. La cuestión no es tanto que las mujeres se constituyan como identidad cultural. La cuestión de fondo es que las

5 Así lo hacen, por ejemplo, Jürgen Habermas (1981) o John Rawls (1996). Vid. Iris Marion Young (1997), Jacqui Alexander y Chandra Talpade Mohanty (1997) y Nancy Fraser (1997).

6 Touraine (1993, p. 431 et seq.) explica claramente la necesidad de oposición y conflicto en una democracia.

7 Así, tanto las “mujeres" como también los "hombres" son categorías políticas y no categorías de esencia natural. Vid. Carol Lee Bacchi (1996, p. 5 et seq.), Monique Wittig (1982, p. 63-68) y también Diana Fuss (1989, p. 41) y Marjorie Garber (1992). 
"mujeres" al constituirse como identidad y categoría política corren el riesgo de tener que contraponerse a otros grupos para hacer valer sus propuestas. Colocar a las "mujeres" como categoría política aparte puede tener el efecto de segregar una serie de temas como "temas de mujeres". Las mujeres se "incorporan" o "añaden" a la agenda política a través de políticas de "formación" o "asistencia" (Bacchi, 1996, p. 84). La igualdad de resultados se interpreta en relación a un proyecto de vida definido en realidad por hombres y no por mujeres (Macklem, 2003, passim; Felice, 2003, p. 163; Baines y Rubio-Marin, 2004, p. 14 et seq.). Desde este punto de vista el inconveniente parece residir en las propias mujeres, que no están preparadas para la vida pública o que tienen que equilibrar el trabajo asalariado con el trabajo doméstico. Pero, muy al contrario, la traba radica en las estructuras políticas y sociales que han generado unos roles y que han definido de determinado modo un proyecto de vida digna. No se puede pedir que las mujeres asuman el rol tradicional de los hombres y, además, mantengan el suyo propio. Esto es exigir una doble vida a las mujeres que es prácticamente imposible de realizar.

Dicho esto, el argumento en contra de las políticas de discriminación positiva $\mathrm{y}$, en especial, de las cuotas, tal y como hoy se presentan e interpretan, tendría que derivar, más bien, del hecho de que no acometen desde su base el sistema patriarcal, sino que suman o añaden a la mujer al sistema impuesto por el hombre. Esto no quiere decir que el uso de las cuotas en los órganos de representación y en las esferas de poder (también en el sector privado) sea fútil, no lo es como medida a corto plazo. Que el problema de la desigualdad esté enraizado en las estructuras sociales no justifica que haya que esperar a un cambio social para tomar medidas político-jurídicas que ayuden al cambio. La esfera política y la social se condicionan mutuamente y es difícil esperar un cambio social sin que las mujeres estén representadas en los órganos de toma de decisiones. Pero, en todo caso, la razón para establecer las cuotas no debe estribar en que las mujeres sean capaces de edificar un mundo mejor, o de que puedan aportar una visión o unos valores distintos. Antes bien, el fundamento se sitúa en la necesidad de fomentar la igualdad de sexos y desarrollar las capacidades cívicas de todos. 
El camino (el medio) actual para hacer efectivo esto es que las mujeres se incorporen de forma real en el discurso político y no, como es lo habitual, que se hagan participar por motivos ajenos a la igualdad (normalmente por fines electorales) ${ }^{8}$. La cuestión jurídica esencial para el anti-sexismo no es intentar que las leyes tengan sexo o vayan dirigidas a uno de los sexos en especial. La cuestión jurídica será más bien la de poner de manifiesto que unas leyes elaboradas sin las mujeres (probadamente infrarrepresentadas en los órganos decisorios y aplicadores del derecho) provocan que la cultura jurídica sea sexista y que el sexo se considere una variable fundamental (Higgins, 1996).

Hay que tener muy claro que el fin de las teorías y políticas feministas tiene que conducir a la construcción de la diferencia entre todos como seres humanos que eligen libremente los resultados o proyectos de vida digna, y no entre mujeres y hombres. La lucha apuesta por conseguir un cambio institucional, jurídico y cultural que cuente por igual con ambos sexos en los círculos decisorios públicos y privados, obligando a compartir cargas y tareas. Para ello se ha de crear ese "espacio social ampliado" de interacción.

Todavía se plantea otro problema a raíz de estas novelas que se añade a la situación de inferioridad de la mujer. Se trata de la cuestión de la justicia social planteada desde el deficiente disfrute de los recursos sociales, culturales y económicos al que se ve avocado el sexo femenino. Durante el siglo XIX la desigualdad en recursos afectaba a un colectivo concreto (el proletariado), pero muy especialmente a las mujeres de ese mismo colectivo y, en cierto modo, también a las mujeres de las restantes clases sociales.

La protagonista de Villette nos ofrece una explicación muy ilustrativa de la justicia social desde la mirada femenina de aquel siglo. La justicia social se identificaba con una loca vestida de rojo que ignoraba a los pobres quienes moribundos lanzaban llamadas de ayuda9. La justicia social no existía como tal, sino más bien identificaba con la beneficencia. El pobre era ignorado por las instituciones sociales y el Estado. Únicamente cuando éste adquiría cierto poder de presión se le concedía una limosna de consuelo o caridad que acallara sus quejas. La actitud de la sociedad liberal estaba

8 Muchas veces los conceptos se crean y usan para satisfacer determinados propósitos políticos (Mulhall, 1987; Edelman, 1988).

9 Vid. el texto reproducido a la cabecera de este trabajo. 
todavía enraizada en la obligación moral de beneficencia, sin decidirse por el establecimiento de una obligación jurídica basada en la solidaridad social. Los principios bandera de la Revolución francesa fueron paralizados para el mantenimiento de los pilares básicos de una sociedad liderada por la burguesía. Sólo un intento de armonización de los conflictos para pacificar y estabilizar y, en definitiva, "controlar" los movimientos emergentes hacía posible la concesión de determinados derechos a la clase trabajadora, generando una suerte de intervencionismo conservador, limitado o subsidiario.

Los problemas en el disfrute de los bienes y recursos disponibles se agudizaban en el caso de la mujer, cuya voz diferenciada critica la "casa de muñecas" en la que viven recluidas las mujeres blancas, de clase media y universitarias, incapaces de ejercitar su libertad real. Esta nueva voz deja sentadas las bases para ir mucho más allá, a fin de incidir en la multiplicidad de opresiones que se solapan en las desigualdades de género, desde las económicas hasta las de tipo racial. De la misma forma plantea la necesidad de establecer una legislación acorde con la idea de solidaridad y justicia social como estrategia conjunta de una política democrática paritaria.

El propósito ahora es impulsar una nueva teoría de la justicia basada más en la pluralidad y diferencia de expectativas, necesidades y bienes, es decir, preocupada por "la potenciación de condiciones reales - económicas, institucionales y culturales -tendentes a provocar resultados realmente justos en los procesos de decisión institucional y en los ámbitos sociales tradicionalmente considerados privados" (Herrera Flores, 2005, p. 114).

Desde otro punto de vista, tanto en Villette como en Insolación, se alude a la injusticia de la organización social y en este sentido se discute hoy sobre una otra metáfora denominada la "conciencia cyborg”, referente a un punto de vista distinto alejado de lo socialmente reconocible en la modernidad (orgánico y tecnológico a la vez), basado además en las realidades superpuestas de la opresión (Herrera Flores, 2005, p. 117 et seq. $)^{10}$. Desde esta conciencia se niega la formulación meramente racional de principios de justicia que deja fuera las diferencias fundadas en la

10 Herrera Flores hace referencia a los dos autores que han tratado principalmente esta metáfora: Antonio Negri (2003) y Donna J. Haraway (1995). 
consideración abstracta del otro para llegar a reconocer sus valores y expectativas generadas a raíz de su propia concepción del bien común (Benhabid; Cornella, 1990). Las propuestas van dirigidas al reconocimiento de un renovado poder constituyente nacido de un nuevo pacto o contrato social que parta de la paridad democrática (Puigpelat Martín, 2005, p. 88 et seq.). Este poder reconocería las diferencias culturales, garantizaría los resultados y superaría las viejas visiones e imposiciones sociales.

En esta concepción de la institución y la actividad política los procesos formales se entrelazan con los informales de la vida social. No se abandona la política, sino que se complementa con otros procesos de discusión y opinión informales. En definitiva, no es solamente pertinente sino imperativo preguntarse por la posibilidad de pensar las identidades sexuales y de género de forma distinta.

\section{CONCLUSIONES: EL PAPEL DE LA NOVELA EN LA CONFORMACIÓN DE UNA NUEVA VISIÓN DEL MUNDO}

En el s. XIX el arte se había convertido gracias a autores como Schelling o Hegel en un reino autónomo que revelaba un universo (Dios, Absoluto) a través de signos sensibles (Shiner, 2004, p. 265 et seq.). Esta forma de expresión artística va a tener una doble cara. Las autoras, en la mayoría de las ocasiones a través de seudónimos masculinos, se veían más o menos libres de realizar ciertas afirmaciones en sus escritos ya que los textos literarios no tenían consecuencias político-jurídicas inmediatas. Con todo, las implicaciones sociales de estas miradas son innegables. De ello se derivan algunos rechazos editoriales y censuras y, en su reverso, el gran éxito de muchas de los escritos publicados entre el público, por entonces, principalmente femenino.

No es de extrañar, por tanto, que durante el siglo XIX la novela sirviera de instrumento para plantear un punto de vista distinto que incluyera la denuncia de la igualdad formal implantada en la sociedad y la legislación, aquella basada en una identidad pública que deja las diferencias relegadas al ámbito privado. Asimismo, se utilizaría como medio para mostrar el malestar de un individualismo abstracto ignorante de las conexiones entre libertad e igualdad, y como crítica de las desigualdades 
sociales, económicas y culturales que establecen importantes diferencias respecto a la capacidad de actuar de los sujetos de distintos grupos.

En este sentido tanto Villette como Insolación son obras ejemplares. Ambas trasmiten una visión femenina que critica la sociedad patriarcal poniendo de manifiesto que las diferencias clásicas entre mujeres y hombres son artificiales, es decir, una construcción o invención moderna que, basada en las distinciones biológicas, se usa para justificar las desigualdades político-jurídicas y socio-culturales de género que niegan que la mujer sea un sujeto racional y que la relegan a la condición de sujeto débil, sensible y necesitado de protección. Realizan, igualmente, una fuerte crítica a la concepción liberal del contrato social que divide esfera pública y privada y de la justicia social todavía organizada con base en una dimensión meramente moral que se despliega a través de la mera beneficencia. Estas denuncias permiten ahora la reconstrucción de la realidad social a partir de un nuevo sujeto político democrático (Young, 1990, passim) que acabe con la separación artificial entre la esfera pública y privada, optando por un "espacio social ampliado" que presente conjunta y dialécticamente los dualismos de esencia ontológica de género. Este espacio ha de dar lugar, asimismo, a una concepción renovada de la justicia social que apele a la dimensión político-jurídica de la misma, y se erija partícipe de la mirada compleja de las realidades solapadas en las opresiones y desigualdades presentes en nuestras sociedades.

\section{REFERENCIAS}

ALEXANDER, Jacqui; MOHANTY, Chandra Talpade (Eds.). Feminist Genealogies, Colonial Legacies, Democratic Future. New York: Routledge Press, 1997.

BACCHI, Carol Lee. The Polítics of Affirmative Action. "Women”, Equality and Category Polítics. London: Sage Publications, 1996.

BAINES, Beverley; RUBIO-MARIN, Ruth. The Gender of Constitucional Jurisprudence. Cambridge: Cambridge UP, 2004.

BENHABID, Seyla; CORNELLA, Prucilla. Teoría feminista y teoría crítica. Trad. de A. Sánchez. Valencia: Alfons el Magnánim, 1990.

BIASE, Paola Gaiotti de. Che genere di politica? I perché e i come della politica delle donne. Roma: Borla, 1998. v. 1.

BRONTË, Charlotte. Villette. Trad. de M. Martín. Madrid: Rialp, 1996.

BRONTË, Charlotte. Jane Eyre. Madrid: España, 1998. 
EDELMAN, Murray. Constructing the Political Spectacle. Chicago: University of Chicago Press, 1988.

FELICE, William F. The Global New Deal. Economical and Social Human Rights in World Politics. Lanham (Md.); Rowman and Littlefield, 2003.

FERNÁNDEZ-LLÉBREZ, Fernando. Identidad, género y sexualidad. Retos inclusivos para la teoría democrática. In: VALENCIA, Ángel; FERNÁNDEZLLEBREZ, Fernando. La teoría política frente a los problemas del siglo XXI. Granada: Universidad de Granada, 2004. p. 85-108.

HERRERA FLORES, Joaquín. De habitaciones propias y otros espacios negados. Una teoría crítica de las opresiones patriarcales. Bilbao: Universidad de Deusto, 2005.

FRASER, Nancy. Justice Interruptus. Critical Reflextions on the "Postsocialist" Condition. New York: Routedge Press, 1997.

FUSS, Diana. Essentially Speaking: Feminist, Nature and Difference. New York: Routledge Press, 1989.

GARBER, Marjorie. Vested Interests: Cross Dressing and Cultural Anxiety. New York: Routledge Press, 1992.

GOLDBERG, Steven. La inevitabilidad del patriarcado. Trad. de A. Martín-Gamero. Madrid: Alianza, 1976.

HABERMAS, Jürgen. Teoría de la acción comunicativa: I. Racionalidad de la acción y racionalidad social, II. Crítica de la razón funcionalista. Trad. de M. Jiménez Redondo. Madrid: Taurus, 1981.

HARAWAY, Donna J. Ciencia, 'ciborgs' y mujeres. La reinvención de la naturaleza. Madrid: Cátedra, 1995.

HIGGINS, Tracy. Anti-Essentialism, Relativism, and Human Rights. Harvard Women's Law Journal, n. 19, p. 89-126, 1996.

IBSEN, Henrik. Casa de muñecas. Trad. de G. de la Torre. Madrid: Edimat Libros; Arganda del Rey, 2005.

LAQUEUR, Thomas. La construcción del sexo. Cuerpo y género desde los griegos hasta Freud. Trad. de E. Portela. Madrid: Cátedra, 1994.

LUCAS, Javier de. Para una discusión de la nota de universalidad de los derecho. (A propósito de la crítica del relativismo ético y cultural). Derechos y Libertades, Madrid, n. 3, p. 259-312, 1994.

MACKINNON, Catharine A. Hacia una teoría feminista del Estado. Trad. de E. Martín. Madrid: Cátedra, 1995.

MACKLEM, Timothy. Beyond Comparison. Sex and Discrimination. Cambridge: Cambridge UP, 2003.

MAYORAL, Marina. "Introducción” a Insolación. Madrid: Espasa Calpa, 1995.

MONEREO ATIENZA, Cristina. Reflexiones críticas sobre la igualdad de género a raíz del Proyecto de Ley Orgánica para la igualdad entre mujeres y hombres aprobada aprobado el 21 de diciembre de 2006. Cuadernos electrónicos de Filosofía del Derecho, n. 15, p.1-12, 2007. 
MONEREO ATIENZA, Cristina. Ideologías jurídicas y cuestión social. Los orígenes de los derechos sociales en España. Granada: Comares, 2007.

MULHALL, Stephen. The Theoretical Foundations of Liberalism. European Journal of Sociology, n. 28, p. 269-295, 1987.

NAGEL, Thomas. Mortal Questions. Cambridge: Cambridge University Press, 1989.

NEGRI, Antonio; HARDT, Michael. El trabajo de Dionisos. Trad. de R. Sánchez. Madrid: Akal, 2003.

OSBORNE, Raquel. La construcción sexual de la realidad. Un debate en la sociología contemporánea de la mujer. Madrid: Cátedra; Universidad de Valéncia, 1993.

PARDO BAZÁN, Emilia. Insolación (Historia amorosa). Ed. de E. Penas Varela. Madrid: Cátedra, 2001.

PUIGPELAT MARTÍN, Federica. Libertad y seguridad en un nuevo contrato social. Anuario de Filosofía del Derecho XXII, p. 83-109, 2005.

RAWLS, John. Liberalismo político. Trad. de S. R. Madero Báez. México: FCE, 1996.

RIVERO MORENO, Yosálida C. La novela realista-naturalista española y su representación de la mujer. Divergencias - Revista de estudios lingüísticos y literarios, v. 1, n. 2, p. 141-156, primavera 2004.

SEN, Amartya. Desarrollo y libertad. Barcelona: Planeta, 2000.

SHER, George. Justifying Reverse Discrimination in Employment. Philosophy and Public Affairs, v. 4, n. 2, p. 159-170, 1975.

SHINER, Larry. La invención del arte. Una historia cultural. Trad. de E. Hyde y E. Julibert. Barcelona: Paidós, 2004.

TOURAINE, Alain. Crítica a la modernidad. Trad. de M. Armiño. Madrid: Temas de Hoy, 1993.

WITTIG, Monique. The Category of Sex. Feminist Issues, v. 2, p. 63-68, Fall 1982.

YOUNG, Iris Marion. Justice and the Politics of Difference. Princeton: Princeton UP, 1990.

YOUNG, Iris Marion. Intersecting voices. Dilemmas of gender, political philosophy, and policy. Princeton: Princeton UP, 1997. 